\title{
Os gestores escolares e a inserção das escolas na comunidade
}

\author{
School managers and integration of schools in the community \\ Los directores de escuelas y la inserción de las escuelas en la comunidad
}

\author{
LeILA MARIA FerReIRA SALLES* \\ LUCIANO PLEZ DE MELO** \\ JOYCE MARY ADAM DE PAUla E SILVA*** \\ DEBORA CRISTINA FONSECA $* * * *$
}

\begin{abstract}
RESUMO - Este trabalho tem por objetivo compreender os modos de inserção de duas escolas na comunidade na qual se situam por meio de depoimentos de gestores escolares. Busca-se investigar as representações dos gestores sobre a comunidade e desvelar os processos de aproximação e/ou distanciamento da escola com o entorno escolar. As respostas dadas pelos gestores foram agrupadas em dois conjuntos temáticos conforme se referiam à comunidade ou a relação escola-comunidade. O estudo indicou que as representações construídas sobre uma comunidade de periferia, percebida predominantemente como uma comunidade problema, se impõe e contribui para que a relação escola-comunidade seja marcada por conflitos e desencontros.
\end{abstract}

Palavras-chave - Gestores escolares. Escola. Comunidade.

\begin{abstract}
This study aims to understand the ways of insertion of two schools located on the outskirts in their community, by testimony of its managers. The aim is to investigate the perceptions of these communities by school managers, and to reveal how far or how close from its vicinity the school is. The responses of school managers were grouped into two thematic clusters as referred to the community or the relationship between school and community. The study indicated that the peripheral community is predominantly perceived as a problematic community. This dominant representation contributes to the relationship between the school and the community be marked by conflicts and divergences.
\end{abstract}

Keywords - School managers. School. Community.

RESUMEN - Este estudio tiene como objetivo comprender los modos de inserción de dos escuelas en su comunidad a través de los testimonios de los administradores de la escuela. El objetivo es investigar las representaciones acerca de la comunidad para los administradores y revelar procesos de aproximación o desapego de la escuela en su comunidad. Las respuestas dadas por los administradores se agruparon en dos conjuntos temáticos de acuerdo con relación à la comunidad o de la relación escuela-comunidad. El estudio indicó que las representaciones construidas acerca una comunidad periférica, predominantemente percibida como una comunidad problemática, se impone y contribuye para que la relación escuela-comunidad ser marcada por conflictos y desencontros.

Palabras clave - Directores de escuelas. Escuela. Comunidad.

\footnotetext{
* Doutora em Educação pela Pontifícia Universidade Católica de São Paulo (São Paulo, SP, Brasil) e professora na Universidade Estadual de São Paulo (São Paulo, SP, Brasil).E-mail: <leila@rc.unesp.br>.

**Mestre em Educação pela Universidade Estadual de São Paulo (São Paulo, SP, Brasil).E-mail: <luciano.plez@terra.com.br>.

*** Doutora em Educação pela Universidade Estadual de Campinas (Campinas, SP, Brasil) e professora na Universidade Estadual de São Paulo (São Paulo, SP, Brasil).E-mail:<joyce@rc.unesp.br>.

****Doutora em Psicologia pela Pontifícia Universidade Católica de São Paulo (São Paulo, SP, Brasil) e professora na Universidade Estadual de São Paulo (São Paulo, SP, Brasil).E-mail: < deboracf@rc.unesp.br>.
} 


\section{INTRODUÇÃO}

A análise da relação da escola com as particularidades culturais, sociais e econômicas dos grupos que a compõem torna-se é uma questão importante. $\mathrm{O}$ imaginário construído sobre a comunidade onde a escola se localiza ou da qual os alunos são provenientes define relações e representações, constrói significações e baliza modos de interpretação de comportamentos. Neste caso, o imaginário construído sobre uma comunidade de periferia que é percebida predominantemente como uma comunidade problema se impõe e contribui para que a relação escola-comunidade seja marcada por conflitos, aproximações e desencontros. As representações sobre a comunidade são adentradas pelo imaginário dos educadores sobre os bairros de periferia urbana e sua associação com pobreza, segregação e exclusão social.

Entende-se neste texto por representação social o processo de assimilação da realidade pelos indivíduos, fruto do modo como eles integram suas experiências, seus valores e informações que circulam no seu meio sobre um objeto social e das relações que estabelecem com os outros homens. Essas representações orientam o comportamento na cotidianidade e são constituídas pelos modos de inserção social do indivíduo, já que são construídas não só pelo dado subjetivo, mas também pelo dado objetivo. Essa definição se coaduna com a de Moscovici (1978), que conceitua representação social como o processo de assimilação e construção da realidade pelos indivíduos, uma modalidade de conhecimento que dá sentido às práticas sociais. A representação social se refere aos significados que as pessoas atribuem a um objeto social. Como diz Sawaia (1993), para Moscovici a função da representação social é orientar a conduta e a comunicação entre os indivíduos e assim está vinculada a um sistema de valores, noções e práticas que dá ao indivíduo formas de se orientar no meio social e material e dominá-lo, oferecendo-lhes um referencial e um marco comum que favorece a instituição de uma realidade consensual. Assim as representações sociais criam e veiculam imagens, valores, opiniões, juízos e informações que são compartilhadas pelos indivíduos como as construídas sobre a comunidade em que a escola se localiza e que ancoram (MOSCOVICI, 1981) o imaginário social a respeito da periferia urbana.

Autores como Lasch (1986) e Sennett $(2002,2006)$ têm apontado que as relações entre as pessoas são caracterizadas por processos simultâneos de integração comunitária e de fragmentação social. A relação que os indivíduos estabelecem com o outro que é percebido como diferente e os limites frente à diferença determinam possibilidades de integração comunitária. Na demarcação das diferenças, nega-se que possa haver similaridades entre indivíduos e grupos diferentes. Assim, os gestores, ao falarem da comunidade de periferia onde as escolas se localizam, tendem a se diferenciar dela, o que contribui para que preconceitos e intolerâncias se façam presentes e para que as relações interpessoais no espaço escolar sejam marcadas por conflitos, confrontos e tensões.

Neste sentido, a comunidade imaginada/esperada remonta a paraíso perdido ao qual "esperamos ansiosamente retornar, e assim buscamos febrilmente os caminhos que podem levar-nos até lá", embora a comunidade real "difere da comunidade imaginária que produz uma sensação de aconchego" (BAUMAN, 2003, p. 9). O espaço escolar, que para os gestores proporcionaria a potencial figuração/desejo de ser um espaço de segurança e aconchego, é na realidade diferente.

O que cria um problema para essa clara imagem é outra diferença: a diferença que existe entre a comunidade de nossos sonhos e a "comunidade realmente existente": uma coletividade que pretende ser a comunidade encarnada, o sonho realizado, (em nome de todo o bem que se supõe que essa comunidade oferece), exige lealdade incondicional e trata tudo o que ficar aquém de tal lealdade como um ato de imperdoável traição. A "comunidade realmente existente" se nós achássemos a seu alcance, exigiria rigorosa obediência em troca dos serviços que presta ou promete prestar (BAUMAN, 2003, p. 9-10).

O compartilhar pressupõe relações entre iguais (GIDDENS, 2002; LASCH, 1983, 1986; SENNETT, 2002). Como então compartilhar e/ou acolher a comunidade de periferia, os alunos e suas famílias percebidos como distintos ou potencialmente traidores do desejado para o espaço escolar?

A relação que os gestores escolares têm tido com o espaço da escola historicamente não tem contribuído para que esse compartilhar possa ocorrer. Observase que, nos últimos anos, a discussão sobre a gestão democrática da educação vem constituindo-se em tema recorrente na literatura. Essa atenção é decorrente do caráter centralizador, burocrático, autoritário e cerceador de práticas participativas que caracterizam o sistema público educacional brasileiro (SILVA, 2006. p. 290), que na prática cotidiana tem dificultado a possibilidade de uma gestão democrática e participativa e de acolhimento dos que são considerados "de fora da escola". Diferentes autores têm apontado a prevalência do monopólio do espaço da escola, em primeiro lugar pela direção e em segundo lugar pelos professores, como bem destaca Mendonça (2001, p. 84):

Diretores, professores e funcionários, com prevalência dos primeiros, ainda monopolizam os foros de participação. A escola pública ainda é vista pelos usuários como propriedade do governo ou do pessoal 
que nela trabalha. O professor comporta-se como dono do seu cargo, dos alunos e de suas classes. O diretor funciona como guardião dessa concepção, evitando interferências de servidores e de pais.

O não reconhecimento do espaço escolar como um espaço coletivo, pertencente não somente aos de "dentro" da escola, mas também aos pais e à comunidade, contribui para o distanciamento da escola em relação a esses últimos e para a dificuldade de negociação dos conflitos que surgem em seu cotidiano. A comunidade imaginada pela escola se choca com a realidade e dessa forma se impõem os valores, os princípios e as regras estabelecidos unilateralmente pela escola, gerando estranhamento em relação aos "de fora", dificultando eue a escola seja um espaço realmente coletivo.

As investigações que temos feito sobre a temática jovens e violência têm mostrado que as escolas estudadas apresentam relações conflituosas com o bairro onde se localizam, com os alunos e suas famílias.

As escolas deste estudo se localizam na cidade de Rio Claro, interior do Estado de São Paulo, em uma região conhecida como Grande Cervezão, que é considerada área prioritária pela Prefeitura Municipal do município para a atuação na prevenção da violência de jovens. Esta região, que compreende vários bairros da cidade, se caracteriza por grande concentração de pobreza, alta densidade demográfica e baixos índices socioeconômicos. Não existem áreas verdes nem áreas destinadas ao lazer da população local. As atividades econômicas estão ligadas ao pequeno comércio e ao setor de serviço informal, representado principalmente por vendedores, cabeleireiras e manicures. Os empregados no setor formal são, em geral, operários com faixa salarial entre 2 a 4 salários mínimos.

Os índices de violência nestes bairros são elevados. O dia a dia da população está ligado à ação da polícia no combate ao crime e ao tráfico de drogas. Muitos jovens residentes na região já tiveram experiências marcantes com a violência, e os casos de problemas familiares, envolvendo o crime e o uso de drogas, é comum.

As escolas objeto deste estudo, aqui identificadas como Escolas 1 e 2, estão distanciadas entre si aproximadamente em 2,4 km, sendo que a Escola 1 localiza-se mais ao interior do complexo de bairros, a 5,1 km do centro da cidade, e a Escola 2 é um pouco mais próxima, distando $3,7 \mathrm{~km}$ do centro.

Os alunos trazem para a escola suas experiências de vida que estão muito ligadas ao contexto social descrito. Quando ocorre uma ação policial, como a prisão de traficantes conhecidos, morte, assassinato ou prisão de parentes de alunos, toda a comunidade escolar fica conturbada, o que afeta, inclusive, o trabalho pedagógico.
A ação policial é comum dentro da Escola 1. Os policiais adentram o prédio para procurar foragidos e até mesmo para realizar "batidas" em alunos supostamente ligados ao crime. Na Escola 2 estas ações são reduzidas.

O conjunto físico dos prédios da Escola 1, circundado por muros e alambrados em alvenaria com indicações de aumento em altura não causam boa impressão. A aparência externa dos prédios sugere abandono. Prevalece uma ideia de penúria, com marcas de vandalismo e invasões. Internamente, a impressão de penúria permanece. A mudança de ambientes ocorre em espaços de baixa luminosidade e cujas aberturas de passagens entre blocos de edificações estão cerradas por grades e cadeados. A escola é feia e escura, e sua imagem é de ruim e violenta. No entanto, a escola é apenas uma continuidade de todo o entorno existente.

$\mathrm{O}$ aspecto físico da Escola 2, embora aparentemente erguida sob a mesma concepção arquitetônica da Escola 1 , sugere uma ideia de cuidado, sem indicativos aparentes de vandalismo e invasões. Os ambientes internos, iluminados, trazem a impressão de fluidez, diluindo a percepção de espaços seccionados.

O objetivo deste trabalho é o de compreender os modos de inserção destas escolas nesta comunidade por meio do depoimento dos gestores escolares: diretores e coordenadores pedagógicos. Busca-se investigar as representações dos gestores sobre a comunidade onde as escolas se localizam e desvelar os processos de aproximação e/ou distanciamento das escolas com o entorno escolar. Estas escolas localizam-se e/ou atendem alunos moradores na periferia urbana pobre da cidade. A referência à periferia neste estudo tem por intenção apenas situar as análises, pois referir-se à periferia implica multiplicidade de questões, entre as quais as relacionadas à segregação e exclusão social (SPOSITO, 2001; BALTRUSIS; D'OTTAVIANO, 2009), não implicando que toda periferia possa ser caracterizada como pobre e o centro da cidade como rico.

Foram feitas entrevistas semiestruturadas com os gestores das duas escolas. Nas entrevistas foi solicitado a eles que caracterizassem a comunidade onde as escolas se localizam, os bairros onde os alunos moram, descrevessem a relação das escolas com esta comunidade e a participação da comunidade nas escolas. Os temas básicos abordados nas entrevistas serviram como eixos norteadores da análise.

As respostas dadas pelos educadores foram agrupadas em dois conjuntos temáticos conforme se referiam à comunidade onde a escola se localiza ou a relação escolacomunidade-escola. As famílias dos alunos são partes da comunidade, de modo que a relação com a comunidade é mediada pela família dos alunos, tanto é que os gestores, ao falarem sobre a comunidade, se remetem à 
relação da escola com a família dos alunos. A análise dos depoimentos foi feita conforme as indicações de Bardin (1977), Bogdan e Biklen (1994).

\section{SOBRE A COMUNIDADE ONDE AS ESCOLAS SE LOCALIZAM}

O diretor da Escola 1 inicia seu depoimento procurando localizar a comunidade onde a escola se situa na malha urbana do município. Segundo ele, como a escola está localizada em um setor periférico da cidade, esta, como esperado, "apresenta diversos problemas sociais que podem ser considerados típicos de uma periferia pobre" como a presença do narcotráfico no bairro, a carência econômica e as privações materiais dos moradores. O coordenador desta escola, mesmo minimizando as condições de carência dos moradores do conjunto de bairros, visto que os alunos possuem celulares e microcomputadores, concorda com o diretor. O coordenador aponta a carência do conjunto de bairros como uma das características que os marca e que se evidencia nos problemas de infraestrutura, no desemprego e/ou nos empregos de caráter temporário dos moradores e na presença do tráfico de drogas.

O diretor da Escola 2 trafega no mesmo percurso do Diretor da Escola 1: localiza a escola na malha urbana da cidade e indica a precariedade do conjunto de bairros onde vivem as crianças que frequentam a escola. Porém, segundo ele, como a escola se localiza no início do conjunto dos bairros, a condição infraestrutural do seu entorno não é tão deficiente e a situação familiar dos alunos que residem próximas à escola não é tão problemática. $\mathrm{O}$ coordenador da Escola 2 corrobora as impressões do diretor afirmando que a infraestrutura do entorno da escola não pode ser descrita como precária e se aproxima em impressão do coordenador da Escola 1 quando menciona que alguns alunos possuem microcomputador e/ou residem em casa própria.

Porem, mesmo que às vezes a precariedade da condição de vida dos alunos não seja tão acentuada, os problemas do entorno da escola pautam as falas dos gestores. Para eles, os principais problemas da comunidade podem ser sumarizados em: insegurança, tráfico de drogas, baixa renda dos moradores, desemprego, empregos temporários desestruturação familiar, ausência dos pais na criação dos filhos, ausência de espaços de convívio e integração para os jovens no conjunto dos bairros. Como exemplifica esta fala do coordenador da Escola 1:

O principal aqui é o tráfico. A gente tem muito aluno envolvido e assim o pessoal que trabalha aqui, ou até vizinhos, comentam que determinados locais tá cheio de alunos no meio do trafico. Geralmente são aqueles que a família já nem olha. Eles ficam pra rua. A família não tem aquela preocupação.
Para os gestores, os contraturnos escolares ociosos são complicadores à vida escolar e muitas vezes impulsionam os jovens a adotarem uma trajetória de vida que pode ser considerada inapropriada:

A questão da segurança, a questão de pouco lazer, a parte cultural para os jovens, porque eles não têm muito o que fazer, são um problema. Eles ficam pelas ruas nos tempos livres em que não têm que estar na escola. Poucos se ocupam no período diverso. Então isso é um dos fatores que leva o jovem a se desviar do caminho correto (Diretor, Escola 2).

Os protagonistas de violência são aqueles que frequentam as portas de escolas em horário que não é horário de aula deles, frequentam as pracinhas, estão o dia todo pela rua. Esses alunos são os jovens que são protagonistas de violência (Coordenador, Escola 2).

A condição de baixa renda da população do conjunto de bairros e a necessidade dos pais de trabalhar não é refletida nos discursos dos gestores como elemento atenuante da ausência deles junto aos seus filhos nos horários diversos à escola. Embora o comportamento dos pais possa ser explicado, não foi feita nenhuma ponderação que o trabalho pode privar os filhos do contato com eles, mas que é plenamente justificável dada a necessidade de sobrevivência:

Às vezes a mãe trabalha 24 horas por dia, não vê a filha. No período que a filha não está na escola não sabe com quem a filha está, onde está, e vem pedir socorro pra nós, pra nós conversarmos, pra nós orientarmos (Diretor, Escola 1).

A ausência de projetos socioculturais na comunidade (ou o desconhecimento por parte dos gestores de projetos deste tipo) sejam eles promovidos por iniciativa de organizações não governamentais ou pelo Estado, juntado às declarações de que as intervenções do poder público local no conjunto de bairros se restringem à melhoria da infraestrutura física, fornecem subsídios à legitimação discursiva dos "contraturnos problemáticos".

Todas essas ponderações dos gestores assinalam que a comunidade é primordialmente percebida pelos problemas que apresenta. Tanto é que os gestores, quando indagados sobre aspectos positivos da comunidade, demonstram estranhamento a respeito da questão proposta. Seguem-se disso discursos que flutuam conflitantes ao então manifesto como problemas da comunidade.

Para indicar aspectos positivos que se fazem presentes na comunidade, os gestores da Escola 1 passam então a elogiar a "garra" das famílias que, mesmo em condições adversas, criam seus filhos dentro do esperado socialmente: 
De positivo? Bom eu acredito que eles têm uma garra assim muito grande. Eles têm os problemas familiares, como muitas famílias que a gente vê. Às vezes é a mãe que é a chefe da família. Alguns têm os pais, o pai ou a mãe ou alguém da família preso. Muitos têm este histórico na família e nós vemos que muitos deles, apesar de tudo isso, ainda conseguem apresentar uma postura, um comportamento, digamos, adequados às normas da escola (Diretor, Escola 1).

Os gestores da Escola 2, por sua vez, respondem a tal questão trazendo a preocupação com a escola e estabelecendo assim certo distanciamento na significação do elemento positivo destacado:

De positivo? Hoje eles têm uma preocupação muito grande com a escola, onde eles querem que os filhos estudem, com a qualidade do ensino da escola que os filhos estudam (Coordenador, Escola 2).

Isto reforça o que começamos a evidenciar que são os problemas da comunidade que são ressaltados nas falas dos gestores. As representações construídas sobre uma comunidade de periferia que é percebida predominantemente como uma comunidade problema se impõem e balizam o relacionamento destas escolas com a comunidade em que se localizam. Em vários momentos parece predominar uma representação de que a comunidade é formada por pessoas drogadas, famílias desestruturadas, jovens ociosos, pais irresponsáveis ou que vivem na ilegalidade estando sujeitos a ser presos a qualquer momento.

Ao se acentuarem os problemas, a relação escolacomunidade vai então se alicerçando baseada em conflitos. As representações construídas sobre a comunidade onde a escola se insere permeiam as relações e suscitam indagações: como se aproximar, como agir, de que modo abrir a escola para a comunidade?

Neste sentido podemos tomar como metáfora Sennett (2005) em sua análise da Veneza shakespeariana para ponderarmos a proposição da escola como potencial espaço em constante processo de desterritorialização:

Muitos estrangeiros estavam integrados a sua sociedade e, na imaginação dos elisabetanos, sua opulência derivava desses contatos com os bárbaros e infiéis de acordos com o Outro. Mas Veneza, ao contrário da antiga Roma, não possuía nenhum poder territorial; os estrangeiros que iam e vinham não desfrutavam de privilégios, não eram membros de um império ou nação-Estado. Residentes na cidade - alemães, gregos, turcos, dálmatas e judeus - não tinham cidadania oficial, vivendo permanentemente como imigrantes. Para abrir as portas das suas riquezas só havia uma chave: o contrato. (SENNETT, 2005, p. 181-182).
Mantidas as proporções e distanciamentos entre venezianos e gestores escolares, os gestores consultados referem-se à comunidade onde se localizam as escolas como um alhures em distinção ao próprio espaço escola; porém, reconhecem que sua eventual "opulência" - da escola como espaço outro - deriva das formas de contato entre escola e comunidade cuja existência de muros/ fronteiras não significa "soberania" do e no espaço escola. Desse modo, a comunidade parece não gozar de uma "cidadania oficial" junto à escola, cabendo, então, a ela para ser aceita e legitimada frente ao espaço escolar a adoção do proposto pela escola como "acordo", ou seja, a aceitação deste contrato para a abertura de seus portões.

A proposição de acordos pela escola para a abertura dos portões físicos ou simbólicos à comunidade pode tanto significar a tentativa de reconhecimento de alguma soberania às práticas internamente instituídas ou, ainda, algum rascunho identitário distintivo de si - escola para com a comunidade demarcando potencialmente os percebidos legitimamente como os de dentro e os de fora da escola.

\section{SOBRE A RELAÇÃo ESCOLA-COMUNIDADE-ESCOLA}

Comunidade e escola se interpenetram. As escolas não estão isoladas da comunidade nem a comunidade apartada das escolas.

Ao ser solicitado a caracterizar a relação escolacomunidade e comunidade-escola, o Diretor da Escola 1 conta que pessoas da comunidade, principalmente pais, alunos e ex-alunos, costumam ir até a escola em busca de orientações. Orientar as pessoas indica para o diretor que a escola tem procurado sempre manter a melhor relação possível com a comunidade. Embora, na maioria das vezes, a ida de pessoas à escola se restrinja a busca de informações sobre aulas, o Diretor diz que os jovens do bairro entram em contato com a escola quando querem se informar sobre cursos supletivos ou resolver dúvidas a respeito de quais cursos frequentar como complementação escolar, como cursos de informática ou inglês. Ocasionalmente, ex-alunos entram em contato com a escola para visitar professores.

O diretor desta escola relata ainda que a comunidade do entorno entra em contato para que a escola a ajude. Pessoas da comunidade parecem esperar que a escola exerça funções assistenciais, ajudando alguma família que está passando necessidades, sejam eles pais ou não de alunos da escola. E, a escola, segundo o diretor, tenta atender a essas solicitações organizando arrecadações para ajudar as famílias necessitadas. Outras vezes, são instituições religiosas evangélicas presentes no bairro que solicitam apoio para realização de almoços, esperando que 
a escola ceda o espaço físico e/ou pratos e talheres. Em geral, a escola, segundo o diretor, procura atender a essas solicitações das quais participam pessoas da comunidade, alunos, ex-alunos e pais de alunos. O coordenador da Escola 1, em sentido oposto, é, por sua vez, categórico ao afirmar a raridade da procura pela escola por parte da comunidade.

Os gestores da Escola 2 pontuam que o contato da comunidade com a escola se resume à busca de informações por parte dos pais sobre o processo de aprendizado dos filhos. Não existe menção a busca por orientações por parte de alunos ou ex-alunos sobre cursos ou atividades de formação complementar. Tanto o coordenador quanto o diretor da Escola 2 são categóricos ao afirmar a inexistência de contato de jovens "não alunos" com a escola. Na Escola 2, em acordo com a fala de seu diretor, a procura da comunidade pela escola ocorre quando da necessidade da divulgação de ações ou programas "educativos" promovidos, por exemplo, pelo pronto-socorro do bairro. A divulgação de campanhas comunitárias, ações ou programas educativos não significa configuração de parcerias.

O espaço físico da Escola 2 parece constituir importante locus a ações e propagação de informações e divulgações de atividades promovidas pela comunidade para a comunidade. Já o espaço físico da Escola 1 parece servir também como facilitador de encontros e reuniões em uma região marcada por carências.

Registra-se que, em ambas as escolas, quando da ocorrência de algum evento ou atividade promovida pela comunidade, os gestores, pelo que constatamos, não costumam comparecer:

Não é que a escola é chamada, a escola é convidada, então se divulgam as atividades que vão ocorrer no bairro. A escola divulga, mas como a gente não mora aqui, então dificilmente a gente vai. Os alunos acabam participando das atividades divulgadas (Diretor, Escola 2).

As escolas, de acordo com os gestores, não participam de atividades organizadas pela comunidade e não desenvolvem atividades direcionadas a ela. Em nenhum momento os gestores, mesmo mencionando contatos com representantes de diversos segmentos da comunidade, levantaram a hipótese de que a escola poderia procurar instituições existentes no entorno para a realização e efetivação de parcerias e trabalhos conjuntos invertendo a direção: ao invés de ser procurada a escola é quem procuraria os representantes da comunidade. A justificativa para a não participação e não proposição de projetos e parcerias ampara-se, segundo os gestores, nas múltiplas funções que as escolas têm que desempenhar:
Ultimamente a gente está tão abarrotado de coisa, de tanta coisa que é cobrada da escola, que isso tá ficando para trás. Porque a escola não é mais só o lugar de aprender conteúdo escolar, é o lugar de aprender que não pode jogar papel no lixo, é o lugar de aprender que tem de escovar os dentes, é o lugar de aprender um monte de coisa que, se não era papel da escola, agora é (Coordenador, Escola 1).

Eu até reclamo com os alunos, eu falo assim: vocês me dão tanto trabalho que a gente não tem tempo de sentar e pensar algum projeto para vocês, alguma coisa diferente (Diretor, Escola 1).

A gente sabe de alguns os projetos que têm, outros a gente nem fica sabendo. E nós estamos em um ritmo de trabalho tão alucinante que você não dá conta nem de resolver os problemas da escola, faltando tempo para estreitar laços maiores com a família e a comunidade. Já foi até melhor, mas hoje está difícil (Diretor, Escola 2).

Sabe, a gente tem ultimamente uma preocupação muito grande com o currículo. Então a escola não tem oferecido atividades extracurriculares para a comunidade. Então nós estamos trabalhando praticamente direcionados para o aluno. Por isso que a gente não tem aberto para a comunidade (Coordenador, Escola 2)

O cotidiano das escolas, sua dinâmica e exigências, configuram-se como complicadores para a elaboração de ações de integração com a comunidade. Parte do tempo que poderia ser destinado a tais ações é preenchido, em ambas as escolas, em processos de disciplinamento dos alunos:

A gente tem que ficar dando bronca, aplicando punições, essas coisas assim (Diretor, Escola 1).

Se eu recebo seis quintas series, duas têm limites e quatro eu tenho que domar, eu tenho que treinar, eu tenho que pôr limites. Ensinar a subir, a descer, a se comportar. É um trabalho que a todo ano é um recomeço. Os alunos saem daqui e vão para outros lugares e acabam voltando para cá. Há uma procura muito grande pela vaga aqui, porque a escola tenta manter uma disciplina, uma ordem para que a coisa não decaia. Então você tem que fazer uma marcação cerrada. E explicar para o aluno, por exemplo, por que não se pode usar boné, porque tem que vir uniformizado, porque tem que vir no horário, porque tem que saber se comportar dentro da sala de aula, porque tem que ter o material todo em ordem, porque tem que fazer o uso do banheiro de uma maneira correta. Então isso é todo dia (Diretor, Escola 2).

Mesmo com a grafia desta ocupação do tempo em processos de disciplinarização, "de domar", certa preocupação em desenvolver atividades que visem a 
uma melhor integração com os alunos e que ocorrem prioritariamente por meio de atividades extracurriculares, existe nas duas escolas. Neste sentido são promovidas atividades extraclasse que visam criar um coral, treinar alunos para jogar em campeonatos esportivos e promover excursões didáticas. Atividades como essas são, segundo os gestores, a forma que a escola tem buscado para suprir a lacunas do conjunto de bairros quanto a espaços de lazer destinados aos jovens. Mas, lembramos aqui, são atividades restritas aos alunos matriculados nas escolas e, pelo menos na Escola 1, são recentes, já que foram implantadas apenas no ano de 2010.

$\mathrm{O}$ diretor da Escola 1 explica que as atividades como as descritas acima não eram realizadas porque os professores tinham medo da maneira como os alunos poderiam se comportar, como diz: "os professores achavam que ia dar problema, mas tem aluno que é tão mal comportado na escola e que vai lá fora e dá um show de bom comportamento". Entretanto, o diretor conta:

Nós vivemos um problema há umas três semanas atrás. Nós tivemos uma festa com os alunos aqui no pátio e na $5^{\text {a }}$ série aconteceu um probleminha entre dois alunos. Um ficou com ciúmes do outro porque estava dançando com uma menininha. Aquilo foi desaguar aqui no portão, na hora da saída. Brigaram com o menino, juntou gente da rua e molecada, gente que nem era da escola. Acabaram batendo no menino e machucando (Diretor, Escola 1).

E, mesmo que as atividades sejam dirigidas apenas aos alunos, os jovens da comunidade tentam, como podem, participar:

Diminuiu agora, mas tem muita invasão. A gente vendia convite, tudo, e ficava alguém na portaria, mas pelo muro pulavam alunos, ex-alunos, que já estavam metidos com droga ou bêbados. Por causa da invasão a gente faz a festa fechada (Coordenador, Escola 1).

Assim, a dúvida entre "abrir" a escola para a comunidade ou restringir seu acesso a eventos organizados por igrejas e aos alunos que estão regularmente matriculados nela parece persistir. A escola aberta à comunidade pode ficar sujeita à presença de intrusos, de pessoas bêbadas e/ou drogadas. Desse modo, o fechamento da escola que acarreta um distanciamento entre escola e comunidade se coloca como alternativa e parece pautar o relacionamento. Reforçando tal prática, o diretor da Escola 1 desloca a escola para um alhures fora da comunidade, apartando-a do que acontece "lá no bairro deles".

Às vezes é coisa que nasceu aqui e vai desaguar lá fora. Às vezes é coisa que aconteceu lá, no bairro deles, que eles vêm desaguar aqui (Diretor, Escola 1).
A quase inexistência de ações de integração ratifica, então, a família como a grande mediadora entre comunidade e escola. O interesse dos pais pela vida escolar dos filhos promove e facilita a integração. Todavia, para os gestores, são poucos os pais que agem deste jeito. Em geral, o desinteresse parece ser a regra:

Olha, aqui nós temos um pessoal muito interessado com o aproveitamento dos filhos. Mas também tem uma parcela considerável de pais que colocou o filho na escola, a vaga está garantida, e ele não sente que tem mais nenhuma responsabilidade de acompanhar o filho na escola. Jogam toda a responsabilidade para a escola. $\mathrm{O}$ trabalho para ser feito tem que ter responsabilidade deles também (Diretor, Escola 2).

A reconhecida precariedade na integração escola/ comunidade, registrada quase em sua totalidade pelo desinteresse dos pais em relação à vida escolar dos filhos e pela sua ausência em reuniões marcadas pelas escolas e em "festas" assinaladas no calendário escolar, reafirma a separação escola/comunidade.

Entretanto, tanto a família como a escola se instituem como instâncias encarregadas da educação das crianças, convergindo e se complementando para tanto. Porém, mesmo neste ponto as divergências parecem predominar. Segundo os gestores escolares, os pais tendem a se desresponsabilizar pela educação de seus filhos imputando à escola essa tarefa:

A escola em geral hoje se torna um aparato social Assim transpõe os limites do só educar. É um aparato social. Então aqui além das matérias em si, a gente tem como meta que eles (os alunos) aprendam a educação formal e também a aprendizagem da convivência, o aprender a conviver também (Diretor, Escola 1).

Eles (pais) jogam toda a responsabilidade para a escola, "cuida porque eu já não sei, mais o que eu faço". Eu acho que eles não têm a solução, então eles acham que a escola pode ter e não tem, porque o carinho da escola não é o mesmo carinho da família. Eu acho que a escola até pode ensinar o que a família ensina, mas desde que a família apoie a escola. Não é só jogar pra escola, não adianta a escola falar que o aluno não pode jogar o papel no chão e em casa ninguém falar (Coordenador, Escola 1).

A família hoje deposita toda a confiança na escola Algumas famílias depositam toda a responsabilidade da formação de seus filhos na escola. E isso não é legal, porque a educação de uma criança é o conjunto da família e da escola. Não se pode atribuir sentido só para uma instituição, no caso aqui a escola (Diretor da Escola 2).

Para eles isso indica que os pais abandonaram o seu papel de pais e que, mesmo quando cobrados para terem 
uma atitude de controle sobre os seus filhos, acabam devolvendo aos professores essa responsabilidade.

Essas falas dos gestores baseiam-se no comportamento que observam dos alunos na escola. Assim sendo, as suas falas vão ao encontro das colocações de Thin (2006) que afirma que os professores criam representações das práticas e do modo de vida das famílias a partir da observação das atitudes dos alunos, como o comportamento, a atenção/ desatenção, a adesão às regras, o tipo de vestuário, as conversas que têm em sala de aula.

Os gestores com isso, apontam que existe um processo de se delegar para a escola a educação das crianças e que este é um problema a ser enfrentado. Neste sentido é que a escola, mesmo com limitações, acaba ensinando para as crianças regras de civilidade.

Esta aparente negligência dos pais aliada à precariedade socioeconômica e cultural da comunidade dão bases e fundamentam as elaborações discursivas sobre o fato de as escolas, na sociedade contemporânea, abarcarem responsabilidades que não eram primordialmente suas. Porém, essas colocações presentes nas falas não dão margem aos gestores para pensarem sobre a necessidade de reelaboração das especificidades da escola na sociedade atual, caminhando, assim, ao encontro da análise de Arendt (2011). Os gestores parecem se limitar a constatar que a escola tem abraçado outras responsabilidades e a se queixarem de que isso esteja ocorrendo. As queixas e lamentos sobre o modo dos pais se comportarem e seus modos de organização familiar (famílias monogâmicas chefiadas só pelas mães, famílias em que os pais, as mães e/ou parentes estão presos, por exemplo) são recorrentes. Chamar as famílias "às suas responsabilidades" parece ser, então, a tônica que permeia as relações:

$\mathrm{Na}$ verdade a escola só entra em contato com a família quando tem problema e isso deveria mudar. A escola deveria chamar os pais dos bons alunos também para falar que o filho é um bom aluno, que é estudioso, o que não acontece. Porque tem tanta coisa pra fazer que a gente acaba só usando os problemas pra chamar os pais (Coordenador, Escola 1).

A primeira relação é de chamar pela responsabilidade. São elas (famílias) que são as primeiras responsáveis pela formação e educação dos filhos. Elas não podem se eximir da educação das crianças de jeito nenhum. E nem sempre elas gostam disso. Mas é a partir daí a parceria da escola com a família, para que essa criança, esse jovem e esse adolescente, estudem. Para que venha para a escola, seja um aluno frequente e tenha um aproveitamento suficiente. Então a escola tenta fazer a parte que lhe cabe dentro da sociedade, como escola, como instituição de ensino. A educação a gente tenta melhorar. Agora sozinha a escola não faz nada. Agora a gente chama para a reunião de pais, o que é muito difícil porque eles não vêm (Diretor, Escola 2).
O coordenador da Escola 2 ratifica a fala de seu diretor quanto ao chamamento da família pela escola: "sempre que a gente percebe que o filho esta passando por algum problema disciplinar a gente chama a família para uma conversa".

A relação da escola com as famílias da comunidade vai então se estabelecendo pautada em conflitos e desencontros. Ora é a escola quem chama a família para reclamar do aluno ou para "chamar as famílias à sua responsabilidade", ora são as famílias dos alunos que vão à escola para reclamar de uma atitude adotada por esta. Embora na Escola 2 não tenha sido mencionado pelos gestores qualquer caso com maior gravidade, o coordenador e o diretor da Escola 1 relatam que a situação de conflito com as famílias se agrava quando a ronda escolar é chamada, seja pela escola seja pelos pais:

Às vezes a situação é tão grave que a gente pede a presença da ronda escolar. Por exemplo, duas meninas se pegam e uma unha o rosto da outra e a outra está com o rosto sangrando. Aí tem que chamar os pais e a ronda escolar pra ver se o pai da agredida vai fazer BO (Boletim de Ocorrência). Aí geralmente o pai do agressor acha que a escola não deveria ter chamado a ronda e o pai do agredido não faz boletim de ocorrência de medo de retaliação (Coordenador, Escola 1).

\begin{abstract}
A mãe que estava no ponto de ônibus esperando o ônibus pra ir trabalhar viu a briga e subiu aqui na escola. Ela veio com sete pedras na mão atacando a escola, dizendo que a escola tinha sido responsável por aquele problema, que nada foi feito. Envolveu até a ronda escolar. A policial veio, fez um B.O. Mas daí a própria polícia e o diretor, que sou eu, conversamos com a mãe tentando mostrar pra ela que o problema pode ter começado aqui, mas que a cem metros da escola a gente não é mais responsável (Diretor, Escola 1).
\end{abstract}

Como estamos indicando, a relação família/escola é marcada por conflitos, tensões, acusações, censuras e elogios. Os gestores ora elogiam a "garra" das famílias e ora as censuram por não oferecerem uma educação considerada adequada a seus filhos, por não os vigiarem, não os disciplinarem e não assumirem suas responsabilidades deixando-os "soltos" por aí. Mas, mesmo com os conflitos e tensões, a presença e importância da família junto à escola é enfatizada por todos os gestores. Seja por meio de: tentativas de acolhimento (diretor da Escola 1); encontros mais habituais com os pais que acompanham a vida escolar dos filhos de forma extemporânea às reuniões (diretor da Escola 2); chamamento dos pais quando há a percepção por parte da escola da existência de algum problema (coordenadores das Escolas 1 e 2). A relação com a comunidade, mediada pelas famílias dos alunos, pode então ser caracterizada como uma relação de distanciamentos e aproximações. 
Mas a aproximação não é fácil. Como se aproximar das famílias e por meio delas da comunidade, visto que a mediação entre escola e comunidade é permeada pelas famílias, se as próprias famílias aparecem nas construções discursivas como um problema? Assim, acolher, não acolher, trazer a comunidade à escola, aproximar-se das famílias que residem lá ou que são pais dos alunos, não parece ser uma questão simples.

A tendência a destacar os problemas presentes na comunidade parece contaminar a forma pela qual os gestores percebem e significam a família, os alunos e a própria comunidade. Esses elementos seguem ao encontro da impressão da escola manter-se como espaço outro em relação à comunidade. A própria dimensão de comunidade parece ser subvertida em razão de alguma impotência dos gestores frente às questões abordadas. Neste sentido, podemos retomar Bauman (2003, p. 103): à medida em que a fala dos gestores, parece conotar para o fazer da escola imaginariamente um abrigo:

O que eles procuram é o equivalente do abrigo nuclear pessoal; o abrigo que procuram chamar de 'comunidade'. A 'comunidade' que procuram é um 'ambiente seguro' sem ladrões e à prova de intrusos. Comunidade quer dizer isolamento, separação, muros protetores e portões vigiados.

Este imaginário, como já mencionado, pode tanto indicar a tentativa de algum delineamento identitário distintivo entre escola/comunidade como o reconhecimento de alguma soberania às práticas internamente instituídas. A busca ou o desejo por alguma soberania interna ou a grafia de algumas marcas identitárias podem seguir neste caso, ainda em acordo com Bauman (2003, p. 106), para a escola afigurar-se a projeto de gueto voluntário, sendo que se "os guetos reais implicam a negação da liberdade. Os guetos voluntários pretendem à causa da liberdade.". Aqui, a liberdade pode refletir ou conotar aquilo que é tomado como peculiar ao mundo escolar, fazendo do seu encerramento em muros a possibilidade de manutenção de sua diferença para com a comunidade. Por sua vez,seu efeito pode ser sufocante:

Seu efeito sufocante é uma 'consequência não prevista' - não é intencional. Os moradores descobrem, decepcionados, que, quanto mais seguros se sentem dentro dos muros, tanto menos familiar e ameaçadora parece a selva lá fora, e mais e mais coragem se faz necessária para aventurar-se além dos guardas armados e além do alcance da rede eletrônica de segurança (BAUMAN, 2003, p. 106).

Assim, ser uma periferia pobre torna-se o eixo central ou o núcleo que pauta as representações dos educadores sobre a comunidade e seus moradores e regula os processos de aproximação e afastamento da escola de seu entorno. A possibilidade da construção da escola como gueto, mesmo voluntário, implica processos de "apagamento" ou diluição de relações ou vínculos com potenciais solidários, pois "um não é um viveiro de sentimentos comunitários. É, ao contrário, um laboratório de desintegração social, de atomização e de anomia" (BAUMAN, 2003, p. 111). Isso reafirma, como aponta Dubet (2005), que é imprescindível investigar o lugar da escola numa estrutura social demarcada pelos mecanismos de exclusão.

\section{GESTORES ESCOLARES E COMUNIDADE: APROXIMAÇÕES E DISTANCIAMENTOS}

No grupo de próximos, onde as pessoas tendem a ser percebidas como iguais, as pessoas se juntam. Os sentimentos de fraternidade e empatia tendem a ser dirigidos ao próprio grupo ao mesmo tempo em que pessoas pertencentes a outros grupos são percebidas como diferentes e tratadas com indiferença, o que facilita atitudes de intolerância e de não aceitação para com eles. Assim, os grupos de pertencimento favorecem as restrições nas relações entre as pessoas ao direcionar a rejeição para aqueles que estão fora do círculo (SALLES, 2009, 2010). Para que as fronteiras entre os grupos sejam demarcadas, o que um grupo tem em comum é colocado em contraste com o que o outro tem. Nesse processo, as diferenças e as similaridades com os outros vão sendo assinaladas. A tendência é expurgar aqueles que não pertencem à comunidade de próximos, excluindo das relações os que são diferentes, contribuindo para diminuir o número de pessoas com quem se julga possível compartilhar (SENNETT, 2002; SALLES, 2009, 2010).

Essas restrições nas relações levam ao fortalecimento de um sentimento de bairrismo de tal modo que, como diz Sennett (2002), as pessoas abandonam a crença na solidariedade de classe em favor de novos tipos de imagens coletivas, baseadas na etnicidade, ou no quartier ou na região. Ser morador de uma comunidade de periferia pobre tem, então, implicações não só econômicas e sociais, mas também simbólicas. As representações que os gestores constroem sobre a comunidade onde a escola se localiza evidenciam esse processo e facilitam uma atitude de reserva, de cautela e precaução, resultando, talvez, como afirma Young (2002), em medo e acentuação do sentido de diferença, indiferença, reserva e cautela da escola frente à comunidade.

Também Wacquant (2007) aponta para o medo que um grupo social tem de tocar outro. Para diferenciar e reafirmar os próprios valores há uma tentativa de estabelecer limites entre virtudes e vícios, de rigidez ao 
julgar, de ser punitivo e excludente. Os bairros pobres são percebidos como local de traficantes, de jovens com antecedentes criminais, de desempregados, de mães solteiras, de pais irresponsáveis, de drogados, dos que vivem da prostituição.

Ser morador da periferia pobre tem implicações simbólicas que justificam o afastamento. Assim, como abrir a escola a essa população se junto com ela vêm os problemas?

Aparece, então, nas falas certa ambiguidade: a comunidade é chamada pela escola em uma tentativa de aproximação, mas é ao mesmo tempo afastada dela. As representações construídas pelos gestores a respeito da comunidade sustentam e dão legitimidade aos processos de exclusão, que, embora sejam determinados macrossocialmente, manifestam-se nas relações cotidianas. Os discursos de lamento sobre a comunidade e as famílias que nela habitam parecem predominar na fala dos educadores.

O deslocamento da comunidade para um alhures é facilitado, abreviado ou encurtado pela adoção de discursos de lamento que estão presentes nas construções discursivas dos gestores e que são amparados na imagem do potencial normatizador/civilizatório da escola. O encontro de elementos subsidiários à exclusão dá margem à desfiguração da escola como corpo cívico (SENNETT, 2005). Aparta-se da escola a possibilidade de espaço de compartilhamento de destinos fazendo dela ponto de convergência de destinos em choque. A escola enquanto pertencente à comunidade constitui-se só como aparência.

A escola não é apreendida como um espaço distinto mas pertencente à comunidade. A escola é percebida como uma instância apartada, embora constantemente invadida pela comunidade.

A adoção do discurso de lamento dá-se como reflexo. Denuncia a invasão de um suposto "eu" por um "outro" constituído, materializado imaginariamente. Este encurtamento, antes de deflagrar visibilidades, denota um mal-estar para os gestores, presentifica a possibilidade de um devir burro ou camelo a singrar desertos sem horizontes (COSTA, 2005).

Dessa forma, o lamento não se constitui como elemento gregário. Distante de promover um compartilhamento de destinos, o lamento provoca apenas momentos de simpatia frente ao percebido como inexorável. O discurso de lamento, assim, mesmo que não se configure estritamente como a fala do ressentido (NIETZSCHE, 2009), flagra a fratura de qualquer possibilidade de vontade de potência. A vontade de potência é diluída em movimentos entrópicos atenuando em equilíbrio a própria potência da vontade frente a recomeços inevitáveis.

O silêncio, o "interdito", ou mesmo o não dito dão margem à interpretação de os gestores figurarem a escola como espaço ideal, ilha de resistência em meio a uma geografia ou mesmo arquitetura opressora. Uma ilha de virtude, como afirmam Dubet e Duru-Bellat (2000), mas uma ilha que tem constantemente suas fronteiras demarcatórias rompidas, invadidas física e simbolicamente, fragmentando o ideário construído a seu próprio respeito.

Nas composições do silêncio e do lamento, abremse margens a uma perspectiva perversa ao apontar a possibilidade de construções ou elaboração de guetos individuados acometidos do fantasma da necessidade de que "pureza requerer segregação" (SENNETT, 2005). Esta escola figurada com fronteiras não só imaginárias, mas visíveis, físicas, que demarcam o fora e o dentro, abarca a possibilidade de constituir-se como espaço guetificado. Um gueto às avessas, invadido e fraturado pela comunidade.

Não cabe à escola caminhar em direção à comunidade ou a comunidade caminhar em direção à escola. A comunidade na escola conota imaginariamente a invasão de um bastião de outrora segurança e tranquilidade.

Isto posto, as possibilidades de efetiva abertura da escola à comunidade, mesmo que seus muros sejam baixados ou os portões escancarados, esbarrará em marcas de resistência pela escola, que se coloca como outra, como espaço distinto, frente à comunidade, ou parcela dela, presentificada imaginariamente e vivificada como potencialmente agressora. Nesse sentido, a "gestão democrática" da escola ou a consideração da mesma como espaço de compartilhamento de poder ou espaço de negociação das diferentes perspectivas de mundo fica muito distante. O estranhamento entre os considerados "de dentro" e os "de fora" da escola reforçam a incapacidade de as famílias e a comunidade compartilharem o espaço e o poder, mantendo-se a escola como propriedade de gestores e professores.

\section{REFERÊNCIAS}

ARENDT, Hannah. Entre o passado e o futuro. 7. ed. São Paulo: Perspectiva, 2011.

BALTRUSIS, Nelson; D'OTTAVIANO, Maria Camila Loffredo. Ricos e pobres, cada qual em seu lugar: a desigualdade socioespacial na metrópole paulistana. Cadernos CRH, Salvador, v. 22, n. 55, p. 135-149, abr. 2009. Disponível em: <http://www.scielo.br/scielo>. Acesso em: 12 abr. 2010.

BARDIN, Laurence. Análise de conteúdo. São Paulo: Edições 70, 1977.

BAUMAN, Zygmunt. Comunidade: a busca por segurança no mundo atual. Rio de Janeiro: Jorge Zahar, 2003.

BOGDAN, Robert; BIKLEN, Sari. Investigação qualitativa em educação: uma introdução à teoria e aos métodos. Porto, Portugal: Porto Editora, 1994. 
COSTA, Sylvio de Souza Gadelha. De fardos que podem acompanhar a atividade docente ou de como o mestre pode devir burro ou (camelo). Educação \& Sociedade, Campinas, v. 26, n. 93, set./dez. 2005. Disponível em: <http://www.cedes. unicamp.br>. Acesso em: 4 nov. 2006.

DUBET, François. O que é uma escola justa? Cadernos de Pesquisa, São Paulo, v. 34, n. 123, p. 539-555, 2004. Disponível em: <http:/www.scielo.br/scielo>. Acesso em: 17 fev. 2005.

DUBET, François; DURU-BELLAT, Marie. L'hypocrisie scolaire: pour un collège enfin démocratique. Paris: Seuil, 2000.

GIDDENS, Anthony. Modernidade e identidade. Rio de Janeiro: Zahar, 2002.

LASCH, Christopher. Cultura do narcisismo: a vida americana numa era de esperanças em declínio. Rio de janeiro: Imago, 1983.

LASCH, Christopher. O mínimo eu: sobrevivência psíquica em tempos difíceis. 3. ed. São Paulo: Brasiliense, 1986.

LASCH, Christopher. Refúgio num mundo sem coração: a família: santuário ou instituição sitiada? Rio de Janeiro: Paz e Terra, 1991

MENDONÇA, Erasto Fortes. Estado patrimonial e gestão democrática do ensino público no Brasil Educação \& Sociedade, v. 22, n. 75, ago. 2001.

MOSCOVICI, Serge. A representação social da psicanálise. Rio de Janeiro: Zahar, 1978.

MOSCOVICI, Serge. On social representations. In: FORJAS, J. (Org.). Social cognition: perspectives on evereday understanding. London: Academic Press, 1981.

NIETZSCHE. Friedrich. Genealogia da moral. São Paulo: Cia das Letras, 2009.

SALLES, Leila. Maria Ferreira. Reflexões sobre jovens, violência e escola. 2009. Tese (Livre Docência) - Instituto de Biociências, Universidade Estadual Paulista, Rio Claro, 2009.

SALLES, Leila. Jovens, escola e violência: alguns apontamentos sobre o processo de inclusão e exclusão simbólica de jovens.
In: SALLES, Leila; SILVA, Joyce Mary Adam de Paula e (Org.). Jovens, violência e escola: um desafio contemporâneo. São Paulo: Cultura Acadêmica, 2010. p. 87-103.

SAWAIA, Bader. Burihan. Representação e ideologia: o encontro desfetichizador. In: SINPK, Mary Jane (Org.). O conhecimento no cotidiano: as representações sociais na perspectiva da psicologia social. São Paulo: Brasiliense, 1993. p. 73-84.

SENNETT, Richard. O declínio do homem público: as tiranias da intimidade. 8. ed. São Paulo: Companhia das Letras, 2002.

SENNETT, Richard. Carne e pedra. 3. ed. São Paulo: Record, 2005.

SENNETT, Richard. La cultura del nuevo capitalismo. Barcelona: Anagrama, 2006.

SILVA, Joyce Mary Adam Paula. Cultura nacional, cultura das organizações escolares e a gestão democrática: algumas reflexões. Gestão em Ação, Salvador, v. 9, n. 3, p. 289-301, set./dez. 2006.

SPOSITO, Marilia Pontes. Um breve balanço da pesquisa sobre violência escolar no Brasil. Educação e Pesquisa, São Paulo, v. 27 , n. 1 , p. 87-103, jan./jun., 2001. Acesso em: 18 maio 2003.

THIN, Daniel. Famílias de camadas populares e a escola: confrontação desigual e modos de socialização. In: MULLER, Maria Lucia Rodrigues; PAIXÃO, Léa Pinheiro. (Org.). Educação, diferenças e desigualdades. Cuiabá, MT: Ed. UFMT, 2006. p. 17-55.

WACQUANT, Loïc. Punir os pobres: a nova gestão da miséria nos Estados Unidos. 3. ed. Rio de Janeiro: Revan, 2007.

YOUNG, Jock. A sociedade excludente: exclusão social, criminalidade e diferença na modernidade recente. Rio de Janeiro: Revan, 2002.

Artigo recebido em agosto 2012.

Aprovado em janeiro 2015. 